\title{
Delivering contraceptive vaginal rings
}

Population Council

Follow this and additional works at: https://knowledgecommons.popcouncil.org/departments_sbsr-rh

Part of the Demography, Population, and Ecology Commons, Family, Life Course, and Society Commons, International Public Health Commons, and the Women's Health Commons How does access to this work benefit you? Let us know!

\section{Recommended Citation}

"Delivering contraceptive vaginal rings," Project brief. New York: Population Council, 2015. 


\section{DELIVERING CONTRACEPTIVE VAGINAL RINGS}

\section{Contraceptive vaginal rings (CVRs) help USAID address an important focus area: Unmet need for familly planning}

To bolster sustainable contraceptive delivery and use, USAID recently proposed a renewed focus, articulating five key areas to address unmet need for family planning: 1) Method Choice, 2) Total Market Approach, 3) Family Planning Workforce, 4) Social and Behavior Communication Change, and 5) Strengthened Supply Systems.

In its "Delivering Contraceptive Vaginal Rings" project, the Population Council has entered into a cooperative agreement with USAID to introduce two new modern contraceptive methods in developing markets: the Progesterone Contraceptive Vaginal Ring (PCVR), a three-month ring designed specifically for spacing while breastfeeding, and an investigational one-year contraceptive vaginal ring-the Nestorone ${ }^{\circledR}$ /Ethinyl Estradiol Contraceptive Vaginal Ring (NES/EE CVR)-that can be used by sexually active women of reproductive age (15-49 years) to delay or space pregnancies.

The Population Council has strategically adopted USAID's five focus areas to introduce PCVR and NES/EE CVR in developing markets.

\section{METHOD CHOICE}

The PCVR and NES/EE CVR will play a key role in expanding choice and increasing access to contraception for millions of women. The unique characteristics of the contraceptive vaginal rings address user needs and current gaps in contraceptive service delivery. The rings are small, flexible, and can be easily inserted and removed to prevent pregnancy.

PCVR and NES/EE CVR are nonclinical contraceptive methods that are controlled by women themselves and, thus, require minimum user and provider skill or time (unlike clinical methods such as injectables, IUDs, and implants). In addition, the rings are discreet and do not interfere with sex. Results from recent clinical trials indicate that most partners cannot feel the rings during sexual intercourse and those who did had no objection.

The Population Council aims to increase method choice by introducing the contraceptives in selected low- and middle-income countries, in a framework of rights and choice.

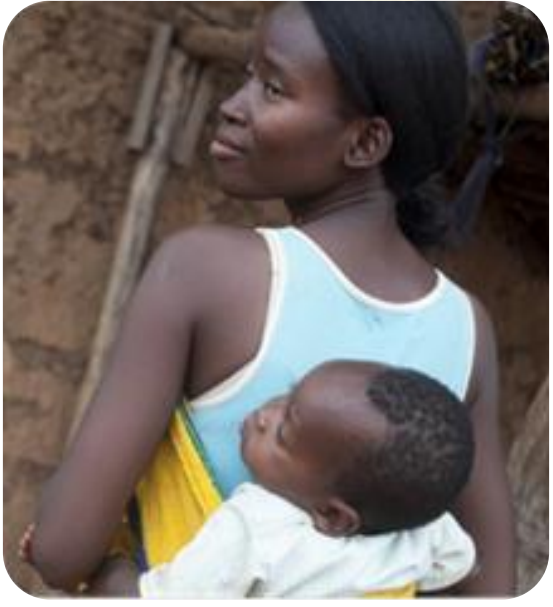

The Population Council is a leading developer of long-acting, reversible contraception.

Council-developed products include the Copper T intrauterine device (IUD), the levonorgestrel intrauterine system Mirena ${ }^{\circledR}$, Jadelle, and Norplant ${ }^{\circledR}$. New products in development include contraceptive vaginal rings and gels and contraception for men. 


\section{FAMILY PLANNING WORKFORCE}

A key challenge to family planning service provision is the shortage of health workers, especially in subSaharan Africa where there are fewer than 2.3 health professionals per 1,000 people (WHO 2006 and 2010). This lack of trained health workers results in reduced access to contraceptive services and products.

The nonclinical provision of CVRs allows for its distribution by lower cadres of health care providers both within communities and health care facilities. Following WHO's "Health Worker Optimization Framework," the Council will incorporate task-sharing and task-shifting mechanisms for distributing the rings by utilizing mid- and lower-level providers.

The task-sharing approach helps higher-level, skilled providers maximize their time for methods requiring clinical provision. Moreover, the PCVR and NES/EE CVR may be distributed by community health workers, which will help lower the cost of service delivery and increase access. Clients will need basic counseling on the use of vaginal rings.

\section{TOTAL MARKET APPROACH}

To reach its target populations in developing countries, the Population Council must work throughout the full spectrum of the contraceptive market, comprising the public, private-commercial, and private-nonprofit sectors.

Rings can be distributed through multiple channels including pharmacies, community outreach workers, depot holders, social franchises, and traditional health care facilities.

The "Delivering CVRs" marketing strategy will utilize a broad spectrum of public and private initiatives and partnerships to reach the entire client market, from those who require free or subsidized rates to those who can, and are willing to, pay for the products. Rings can be included in service packages that are covered by voucher systems, social marketing channels, and by bundling and integrating services.

\section{SOCIAL BEHAVIOR COMMUNICATION CHANGE}

Efforts to effect social behavior communication change (SBCC) will be adopted to not only empower women and inform them of their contraceptive options (including information on the benefits of CVRs) but to create an enabling environment for sustained access and use.
Because the CVR is a new method of contraception, multiple communication tools and informational materials will be developed in a variety of formats to educate consumers, communities, service delivery providers, and key stakeholders.

A marketing manual and stakeholder communication plan are under development describing promotional and implementation strategies among stakeholders and beneficiaries. For example, materials about the rings (including posters, leaflets, and banners) will be designed for health care providers and community health workers to disseminate. Policy briefs and a statement about the value proposition of the rings are being formulated to engage key stakeholders from ministries of health and advocacy organizations. Training materials, counseling programs, and tools will be integrated into the family planning programs of the countries where the rings are introduced.

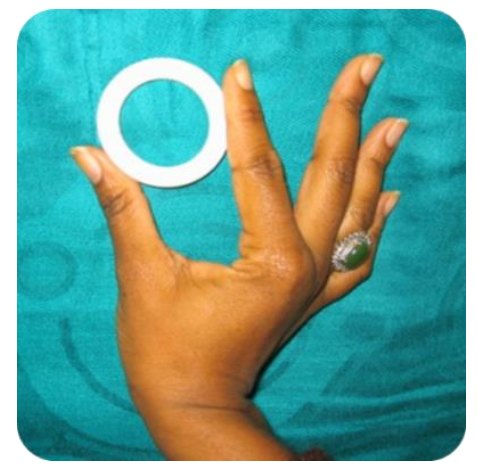

\section{SUPPLY SYSTEMS}

Recognizing that new technologies need to be integrated into existing procurement and logistics systems, the Council is engaged in identifying key local procurement and distribution channels and having them effectively liaise with the licensed manufacturers for both rings.

The Council will engage with established global procurement agencies such as UNFPA, Crown Agents, DKT, and central governmental agencies to ensure higher volume purchases, lower costs, improved shipment services, and better stock-out management. A local logistic management system (USAID/DELIVER PROJECT 2011) will be identified or developed to ensure consistent supply of PCVR and NES/EE CVR for the various service delivery points.

\section{References}

USAID. 2011. "The Logistics Handbook: A Practical Guide for the Supply Chain Management of Health Commodities." Arlington, VA: USAID| DELIVER PROJECT.

WHO. 2010. "Achieving the health-related MDGs. It takes a workforce!" www.who.int/hrh/workforce_mdgs/en/.

_. 2006. "New global alliance seeks to address worldwide shortage of doctors, nurses and other health workers." www.who.int/ mediacentre/news/releases/2006/pr26/en/ 